\title{
Performance Enhancement of a Hybrid AC-DC Microgrid Operating with Alternative Energy Sources Using Supercapacitor
}

\author{
Jayalakshmi N.S. \\ Department of Electrical and Electronics Engineering \\ Manipal Institute of Technology, Manipal Academy of Higher Education \\ Manipal, India - 576104 \\ jayalakshmi.ns@manipal.edu
}

\section{Pramod Bhat Nempu}

Department of Electrical and Electronics Engineering

St Joseph Engineering College

Vamanjoor, Mangalore, India - 575028

pramodb@sjec.ac.in

\begin{abstract}
Microgrids with non-conventional energy sources have become popular recently. Hybrid AC-DC microgrid (HMG) architecture is effectual as it avoids several power conversions for the consumers. Therefore, this article presents a comprehensive study on grid-tied HMG with PV array and wind energy conversion system (WECS) as principal sources. Fuel cell (FC) acts as the auxiliary source in the DC subgrid and the supercapacitor (SC) is used for instantaneous energy management. The hydrogen storage system is used to store surplus power produced by the PV array. The power flow between the subgrids is regulated using the interlinking converter (ILC) by a PQ controller. The main contribution of this article is the comparative investigation of system operation in the HMG configuration in the presence and absence of a supercapacitor bank on the DC bus. The maximum DC bus voltage fluctuation during load variations in the absence and presence of SC bank is found to be $6.6 \mathrm{~V}$ and $3.9 \mathrm{~V}$ respectively. Similarly, the maximum transient fluctuation in the power supplied to the DC load is found to be $830 \mathrm{~W}$ in the absence of SC bank and $340 \mathrm{~W}$ in the presence of SC bank.
\end{abstract}

Keywords - fuel cell, fuzzy logic controller, hybrid AC-DC microgrid, power management, supercapacitor

\section{INTRODUCTION}

Due to increasing pollution, depleting fossil fuel resources and rising energy demand, the need for utilizing non-conventional sources of energy in power systems has increased. Sunlight and wind are available abundantly in nature and can be conveniently used to extract electrical power. The energy sources and storage devices supplying load operating either off-grid or on-grid together constitute a microgrid (MG). The MGs are dynamic systems characterized by continuous variations in load and generation. Many researchers are working on microgrids powered by renewable sources. MGs can work in DC MG, AC MG and HMG configurations. The energy sources and storage devices are integrated into a DC bus in DC MG architecture and to an $A C$ bus in an AC MG structure. HMG consists of DC and $A C$ subgrids. This configuration is reliable and efficient.

An autonomous PV-FC-SC system is investigated in [1]. The SC bank is used to facilitate power balance during abrupt power changes. In [2], a study on a gridcoupled PV-wind hybrid system is presented. The modelling and control techniques are discussed in detail. Paper [3] presents a survey of various maximum power point tracking (MPPT) controllers for WECS.

In [4], the control techniques for the DC MG comprising of a grid-independent PV-WECS-FC-SC hybrid system with electrolyzer (EL) are presented. The SC system is controlled to supply/absorb power during a sudden mismatch in generation and demand.

In [5], the grid-tied hybrid system involving WECS and FC is described in the presence and absence of a storage system. The MG system showed improved power and voltage regulation in the presence of storage systems. The grid integration of the WECS-PV-FC system is described in [6]. The system exhibited satisfactory performance by the control techniques employed for MPPT and power management. In [7], a detailed analysis of the AC MG is presented with PV and FC systems. However, the authors did not consider storage devices for the analysis. 
In [8], an autonomous MG with PV, WECS and FC is analyzed for single-phase systems with a new MPPT control strategy. The application of artificial intelligence for computing the optimal controller gains in a MG is detailed in [9]. The control techniques of PV and WECS based HMG are described in [10]. In [11], a normalized droop control strategy is explained with an experimental study for stand-alone operation of the HMG. In [12], the control strategies and control requirements of different MG architectures are provided and different control techniques for MGs are reviewed.

Paper [13] discusses a model predictive control algorithm for regulating the $\mathrm{DC}-\mathrm{AC}$ bidirectional converter. In [14], the control schemes are proposed for regulating the HMGs under pulsed load conditions. The benefits of D-FACTS in a HMG are evaluated in [15]. In [16], the authors proposed a decentralized control strategy for the power management of a HMG with PV array, WECS and FC and its success is assessed for unbalanced and non-linear loads. A robust control technique for a HMG with the PV array, WECS, diesel generator and battery is developed in [17]. Since diesel generator is known to cause harmful emissions, it can be excluded in MGs.

The output of the ILC or inverter contains higher-order harmonics. Generally, an L filter is used for filtering the harmonics. The price of $L$ filter for bulk power applications is high and dynamic response of the system might be slow. LCL filter is proved to be effective in suppressing the harmonics created due to switching, but it creates a problem of resonance. Therefore, the design of the LCL filter must be carefully carried out to ensure stability, taking into account the correct resonance frequency to obtain a smooth sinusoidal supply for gridtied MGs. The filter design is described in [18-20]. The usefulness of fuzzy logic controllers (FLC) in regulating the MGs is proved in [21,22]. Thus in this work, to control the SC system, FLC is employed.

The application of metaheuristics in optimizing the control parameters in HMGs is described in [23]. The system is verified in the hardware in loop platform. A robust control scheme for the better dynamic performance of a HMG is proposed in [24]. Passivity based approach is found to be effective. The automatic centralized MG controllers for the energy management of the HMG are experimentally demonstrated in [25]. A coordinated frequency control system for HMGs is described in [26]. 98.2\% efficiency was achieved with that control scheme.

This research paper [27], explores the control techniques for the HMG with same energy sources in autonomous mode, while this article analyses the HMG in grid-tied mode. In [28], the DC MG architecture is considered and the FLC is used in voltage and frequency control scheme.

There is sufficient study on improving the dynamic performance of control schemes in the HMGs in literature. However, the existing literature doesn't provide a detailed study on the operation and control of HMG functioning with several renewable sources of different characteristics. The impact of SC bank on individual subgrids in HMGs has not been explored thoroughly. SC is characterized by high power density and can be used for effective handling of power fluctuations if appropriately regulated with suitable control scheme. The significant contributions of this research are:

- The extensive analysis of a grid-tied HMG in the presence and absence of the storage system when the renewable sources with unpredictable output such as PV array and WECS are situated on both buses.

- Investigation of the significance of SC bank in improving the dynamic performance of the HMG under intermittent system conditions considered in both DC and AC buses.

This paper analyses the power flow within and between the subgrids of the grid-tied HMG in detail. In addition, the role of SC bank regulated by FLC based controller in minimizing the transient fluctuations is highlighted.

\section{CONFIGURATION OF THE HMG}

The schematic outline of the HMG considered for the study is presented in Fig. 1. The PV array that can produce up to $21.7 \mathrm{~kW}$ under standard conditions is one of the main energy sources. The single diode model of PV cell is used. The PV array is modelled as described in $[1,2]$. The current output of the PV array $\left(I_{P V}\right)$ is given by

$I_{P V}=N_{p} \times I_{p h}-N_{p} \times I_{r}\left[\exp \left\{\frac{q \times\left(N_{p} V_{o}+N_{s} I_{o} R_{s}\right)}{N_{s} N_{p} k T_{c} n}\right\}-1\right]$

Where $T c$ is the absolute temperature of a solar cell, $r$ is the reverse saturation current, $q$ is the charge of a single electron, $k$ is the Boltzmann's constant, $N_{p}$ and $N_{s}$ are respectively, the number of cells in parallel and series, $R_{p}$ and $R_{s}$ represent the shunt and series resistance of a PV cell, respectively, $V$ represents the voltage output of a PV cell and $I_{o}$ is the current output of the cell, $I_{p h}$ is the photovoltaic current and $n$ is the cell idealizing factor.

A 20 kW WECS with permanent magnet synchronous generator [2] is another main energy source employed in this work. The power obtainable in the turbine $(P)$ is calculated as

$$
P=\frac{1}{2} \rho A C_{P} v_{w}^{3}
$$

Where $A$ is the swept area of the rotor, $v_{w}$ is wind speed, $\rho$ represents the density of air and $C_{p}$ is the coefficient of performance.

A $10 \mathrm{~kW}$ FC system is the ancillary source for the DC bus. Modelling of the FC stack and EL system is detailed in $[1,4]$. The output power of a FC stack is given as a 
function of partial pressure $(p)$ of $\mathrm{H}_{2}, \mathrm{O}_{2}$ and water and flow rate $(q)$. The output voltage of the $\mathrm{FC}$ is obtained by adding the Nernst instantaneous voltage (E) and losses. $\mathrm{E}$ is given by

$$
E=N_{O} \times\left[E_{O}+\frac{R T}{2 F} \times \log \left(\frac{p_{H_{2}} \times \sqrt{p_{O_{2}}}}{p_{H_{2} O}}\right)\right]
$$

$N_{o}$ is the number of cells in series, $E_{0}$ is the no-load voltage (V), F is Faraday's constant, $R$ is the universal gas constant and $T$ is the absolute temperature. A $10 \mathrm{~kW}$
EL system is used to generate hydrogen when the PV system's output power exceeds the DC load demand.

The SC bank of $4 \mathrm{~F}, 400 \mathrm{~V}$, assists in managing power fluctuation created by variations on both subgrids. The PV system operates in MPPT mode. The WECS is regulated by a MPPT controller [2]. Power converters are designed based on the procedure given in [29]. Then the output of the boost converter of WECS is delivered to the $A C$ bus that is integrated into the grid (100 MVA, $3.3 \mathrm{kV}$, and $50 \mathrm{~Hz}$ ) through the transformer. The DC and AC buses are coupled through an interlinking converter controlled using the $\mathrm{PQ}$ control scheme. The dynamic simulation of the HMG is carried out in MATLAB/Simulink software.

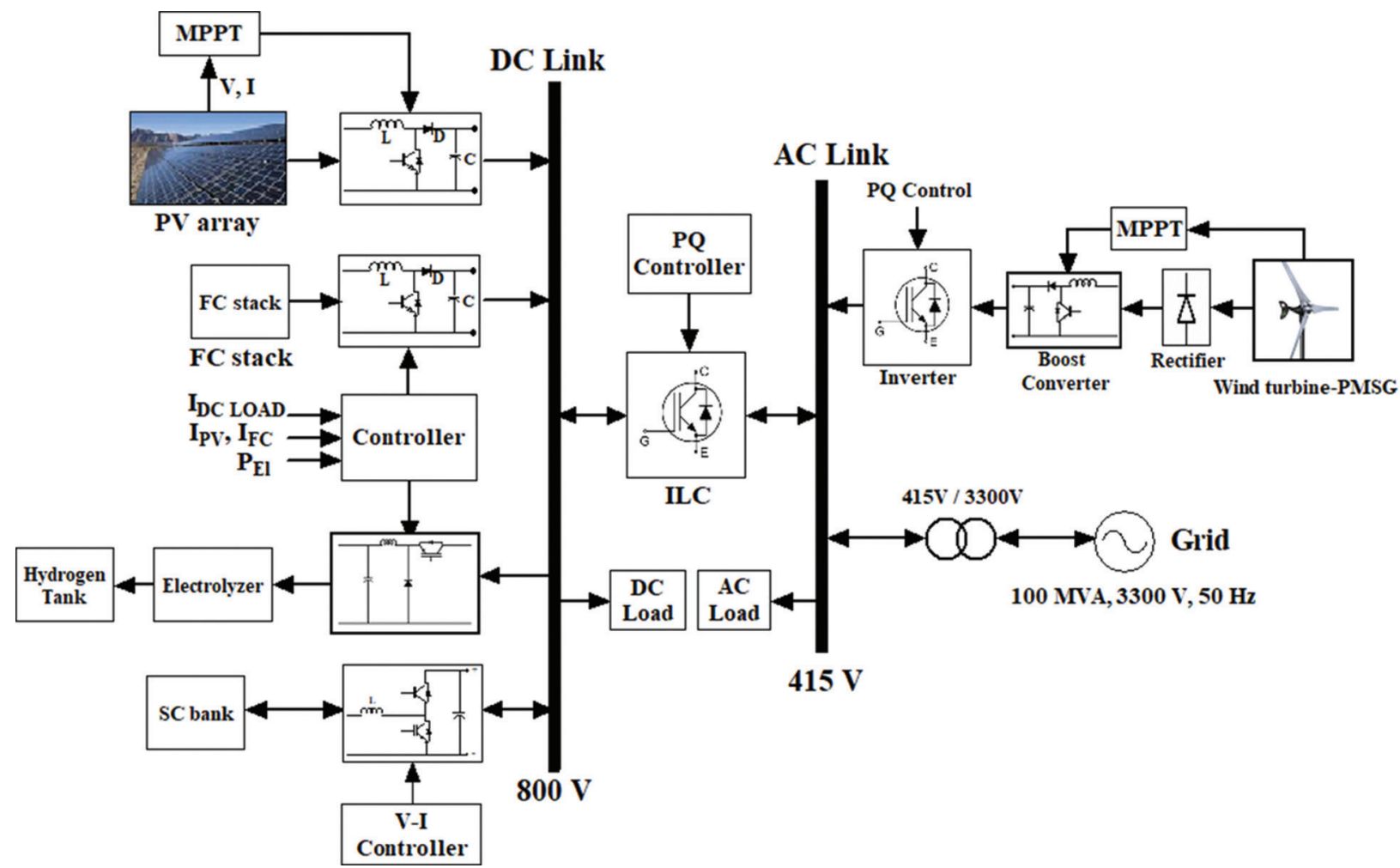

Fig. 1. Schematic representation of the HMG

\section{CONTROL STRATEGIES AND DESIGN OF THE FILTER}

In this section, control techniques used for regulating the HMG and the design methodology of the $\mathrm{LCL}$ filter are depicted in detail.

\subsection{CONTROL STRATEGY OF FC SYSTEM}

The control method of the FC system is depicted in Fig. 2. It is realized using a PI controller. When the DC load goes above the PV power, the FC supplies the additional power required to meet the demand. The current corresponding to the power deficit $\left(I_{D C L O A D}-I_{P V}\right)$ is the reference and the feedback is the current from the output of the boost converter of the FC system $\left(\mathrm{I}_{\mathrm{FC}}\right)$. The controller makes the error zero by computing the ap- propriate duty ratio for the boost converter making the FC stack produce the power required to meet the DC load demand.

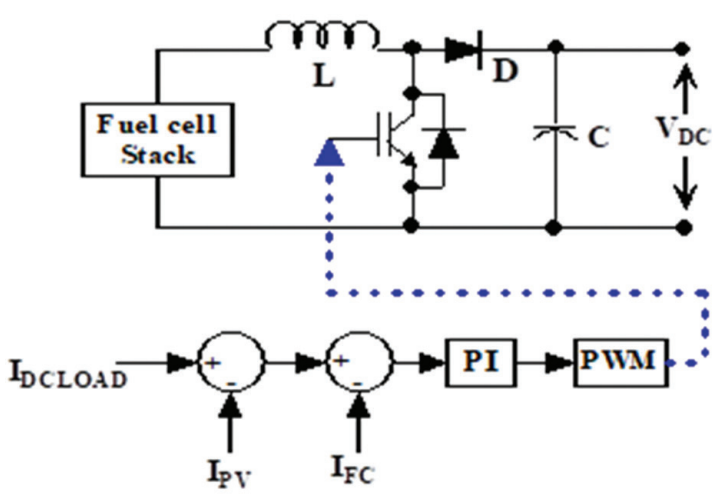

Fig. 2. FC system controller 


\subsection{CONTROLLER OF THE ELECTROLYZER}

The power controller used to control the EL is shown in Fig. 3. A PI regulator is employed to realize it. When the $D C$ load $\left(P_{D C L O A D}\right)$ is smaller than PV power $\left(P_{P V}\right)$, the excess power generated is given as the reference to the electrolyzer. The electrolyzer power $\left(\mathrm{P}_{\mathrm{EL}}\right)$ is taken as feedback. Based on the duty ratio of the buck converter computed by the controller, the power sent to the EL varies. The hydrogen is produced by the EL based on the current through it. The produced hydrogen is then stored.

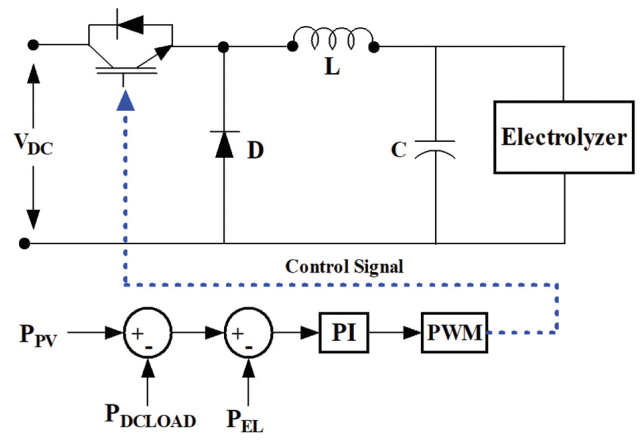

Fig. 3. The power controller of the electrolyzer

The FC and EL systems are responsible for the energy management of the DC subgrid. In this work, FC and EL systems are treated as separate systems for designing the controllers.

\subsection{CONTROLLER OF SC BANK}

Fig. 4 illustrates the V-I controller [30] of the SC bank. It has two loops. Depending on the DC bus voltage $\left(V_{D C}\right)$, the external loop determines the current requirement of SC Bank, and the internal loop controls the SC bank's output current. The outer loop is realized with the FLC. The inputs to the FLC are error $(\mathrm{E})$ and change in error (CE). The current reference of SC bank is the output. The triangular membership functions (MFs) used in FLC are shown in Fig. 5. The centroid method of de-fuzzification is incorporated. To design the rule base, FLCs developed in [21, 22] are taken as reference. This control scheme regulates the DC bus voltage and also facilitates immediate energy management based on the rise or fall of DC bus voltage.

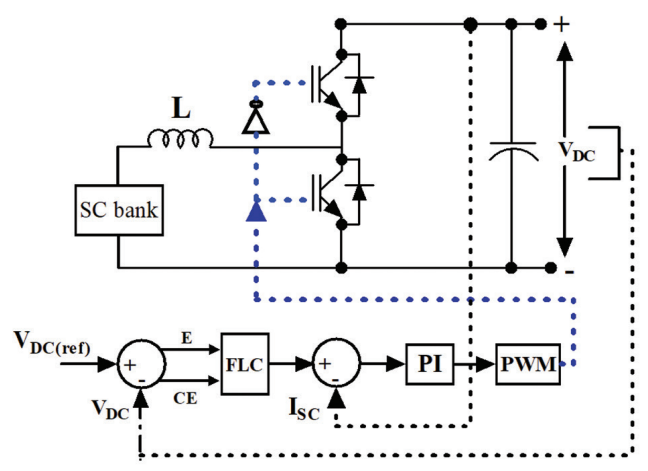

Fig. 4. V-I controller of SC bank

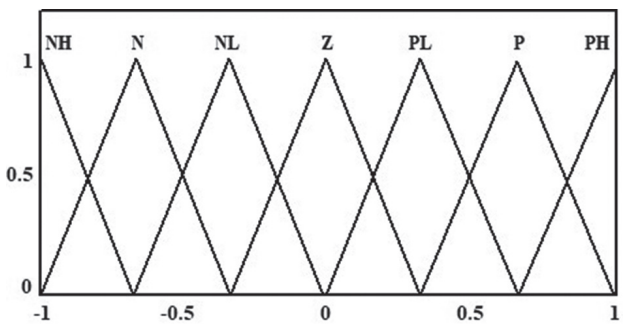

Fig. 5. MF used in FLC

Table 1 presents the rule base of FLC. The MFs are expressed in linguistic variables as Positive High $(\mathrm{PH})$, Negative High (NH), Positive Low ( $\mathrm{PL})$, Negative Low $(\mathrm{NL})$, Positive (P), Negative (N) and Zero (Z).

Table 1. The fuzzy logic rule base

$\begin{array}{cccccccc}\boldsymbol{E} / \boldsymbol{C E} & \boldsymbol{N H} & \boldsymbol{N} & \boldsymbol{N L} & \boldsymbol{Z} & \boldsymbol{P L} & \boldsymbol{P} & \boldsymbol{P H} \\ \boldsymbol{N} \boldsymbol{H} & \mathrm{NH} & \mathrm{NH} & \mathrm{NH} & \mathrm{NH} & \mathrm{N} & \mathrm{NL} & \mathrm{Z} \\ \boldsymbol{N} & \mathrm{NH} & \mathrm{NH} & \mathrm{NH} & \mathrm{N} & \mathrm{NL} & \mathrm{Z} & \mathrm{PL} \\ \boldsymbol{N L} & \mathrm{NH} & \mathrm{NH} & \mathrm{N} & \mathrm{NL} & \mathrm{Z} & \mathrm{PL} & \mathrm{P} \\ \boldsymbol{Z} & \mathrm{NH} & \mathrm{N} & \mathrm{NL} & \mathrm{Z} & \mathrm{PL} & \mathrm{P} & \mathrm{PH} \\ \boldsymbol{P L} & \mathrm{N} & \mathrm{NL} & \mathrm{Z} & \mathrm{PL} & \mathrm{P} & \mathrm{PH} & \mathrm{PH} \\ \boldsymbol{P} & \mathrm{NL} & \mathrm{Z} & \mathrm{PL} & \mathrm{P} & \mathrm{PH} & \mathrm{PH} & \mathrm{PH} \\ \boldsymbol{P H} & \mathrm{Z} & \mathrm{PL} & \mathrm{P} & \mathrm{PH} & \mathrm{PH} & \mathrm{PH} & \mathrm{PH}\end{array}$

\subsection{THE PQ CONTROLLER}

The interlinking converter is controlled by the PQ controller [2, 31]. This controller manages the power exchange between the buses and regulates $V_{D C}$. The PQ controller is shown in Fig. 6.

The power in a 3 phase system is expressed as

$$
P(t)=v_{a} i_{a}+v_{b} i_{b}+v_{c} i_{c}
$$

The active and reactive power $(P$ and $Q$ ) in terms of the direct and quadrature axis voltages $\left(V_{d}\right.$ and $\left.V_{q}\right)$ and current $\left(I_{d}\right.$ and $\left.I_{q}\right)$ are given by,

$$
P=1.5\left(V_{d} I_{d}\right) \text { and } Q=1.5\left(V_{d} I_{q}\right)
$$

The controller's outer loop regulates the $V_{D C}$ and the inner loop controls the currents. The outer control loop computes the $\mathrm{d}$-axis current reference for regulating $P$. In this work, the reference value of $I_{q}$ is zero to ensure the power exchange at unity power factor. The inverter of WECS is also regulated by a similar PQ control scheme. The energy balance across the filter is given by

$$
\left[\begin{array}{l}
V_{d}^{1} \\
V_{q}^{1}
\end{array}\right]=R_{f}\left[\begin{array}{l}
I_{d} \\
I_{q}
\end{array}\right]+L_{f} \frac{d}{d}\left[\begin{array}{l}
I_{d} \\
I_{q}
\end{array}\right]+L_{f}\left[\begin{array}{cc}
0 & -\omega \\
\omega & 0
\end{array}\right]\left[\begin{array}{c}
I_{d} \\
I_{q}
\end{array}\right]+\left[\begin{array}{c}
V_{d} \\
V_{q}
\end{array}\right]
$$

Where $\omega$ is the angular frequency, $L_{f}$ and $R_{f}$ are the total inductance and resistance of the filter, respectively. The transfer function of the PQ controller (ignoring the disturbances and feed-forward) is presented in Fig. 7 [31]. 


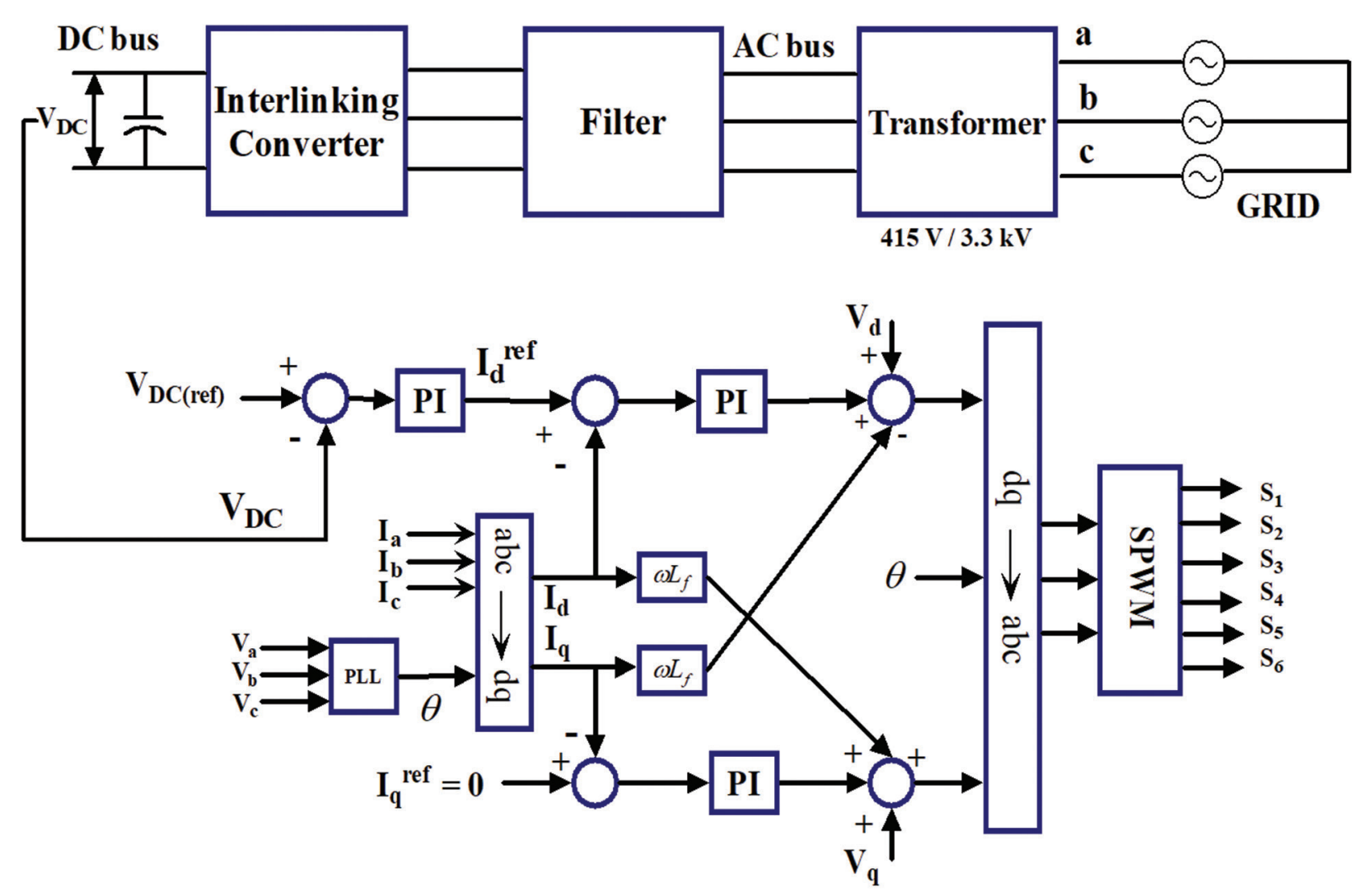

Fig. 6 PQ controller

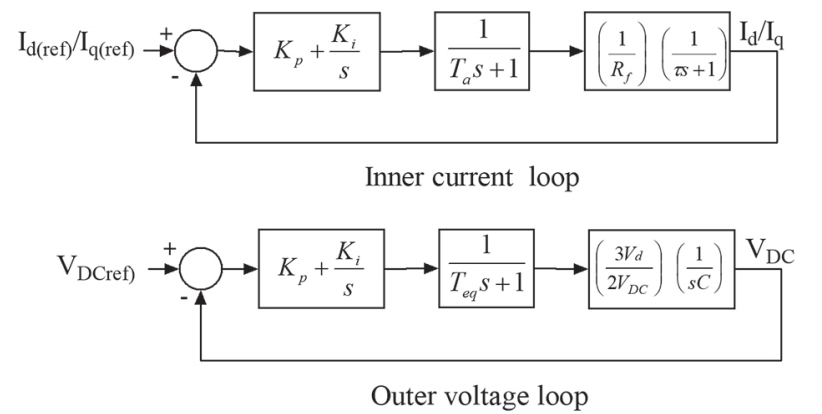

Fig. 7. The transfer function of the $P Q$ controller

Where $K p$ and $K i$ represent controller gain values and $C$ represents DC-link capacitance $(5 \mathrm{mF})$. The time constants in the transfer function ( $T a, T e q$ and $\tau$ ) are expressed as follows.

$$
\begin{gathered}
T_{a}=\frac{1}{2 f_{s w}} \\
T_{e q}=2 T_{a} \\
\tau=\frac{L_{f}}{R_{f}}
\end{gathered}
$$

\subsection{DESIGN OF THE FILTER}

If $V$ represents the voltage, $P$ is power, $f$ is the grid frequency, $f_{s w}$ is the switching frequency $(10 \mathrm{kHz}), f_{r}$ is the resonance frequency, $L_{1}$ and $L_{2}$ are the ILC/inverter side and grid side inductors respectively, $C_{f}$ is the filter capacitor, $R_{d}$ is the damping resistance and $\Delta I_{L(\max )}$ is the maximum ripple current allowed, then equations for designing the filter [18-20] are as follows.

$$
\begin{gathered}
Z_{b}=\frac{V^{2}}{P} \\
C_{b}=\frac{1}{2 \pi f \times Z_{b}} \\
L_{1}=\frac{V_{D C}}{6 f_{s w} \Delta I_{L(\max )}} \\
\Delta I_{L(\max )}=0.1 \times \frac{P \sqrt{2}}{3 V}
\end{gathered}
$$

The $C_{f}$ is calculated as $5 \%$ of its base value [18].

$$
C_{f}=0.05 C_{b}
$$

Based on the attenuation required $\left(k_{a}\right), L_{2}$ can be computed as

$$
L_{2}=\frac{\sqrt{\frac{1}{k_{a}^{2}}}+1}{C_{f}\left(\omega_{s w}\right)^{2}}
$$


The resonance frequency is computed as

$$
f_{\text {res }}=\frac{1}{2 \pi} \sqrt{\frac{L_{1}+L_{2}}{L_{1} L_{2} C_{f}}}
$$

The $f_{r}$ should satisfy the equation

$$
10 f<f_{r}<0.5 f_{s w}
$$

A damping resistor $R_{d}$ is included in series with the $C_{f}$.

$$
R_{d}=\frac{1}{6 \pi f_{r} C_{f}}
$$

The design values are: $L_{1}=5.86 \mathrm{mH}, L_{2}=0.246 \mathrm{mH}_{1} C_{f}$ $=6.16 \mu \mathrm{F}$ and $R_{d}=2.06 \Omega$.

The transfer functions of the filter [20] are given in equations (19) and (20). $G_{1}(s)$ and $G_{2}(s)$ represent the transfer functions without and with $R_{d}$ respectively.

$$
\begin{gathered}
G_{1}(s)=\frac{1}{L_{1} C_{f} L_{2} s^{3}+\left(L_{1}+L_{2}\right) s} \\
G_{2}(s)=\frac{C_{f} R_{d} s+1}{L_{1} C_{f} L_{2} s^{3}+C_{f}\left(L_{1}+L_{2}\right) R_{d} s^{2}+\left(L_{1}+L_{2}\right) s}
\end{gathered}
$$

\section{RESULTS AND DISCUSSION}

The results of the analysis are presented in two subsections. In the first subsection, the results corresponding to the power management are presented. In the second subsection, the benefits of integrating the SC system on the HMG are analyzed.

\subsection{OPERATION OF THE HMG}

The step inputs are given to the PV array and WECS to investigate the operation of the HMG under intermittent conditions. The DC load demand and the power output of sources and storage devices in the DC subgrid are presented in Fig. 8. The FC system produces additional power needed $\left(\mathrm{P}_{\mathrm{FC}}\right)$ to meet the demand and SC bank operates quickly under sudden variations in the system conditions. The surplus PV power generated is consumed by the EL $\left(P_{E L}\right)$. Based on the EL current, hydrogen is produced. The hydrogen production and pressure variation in the storage tank are shown in Fig. 9.

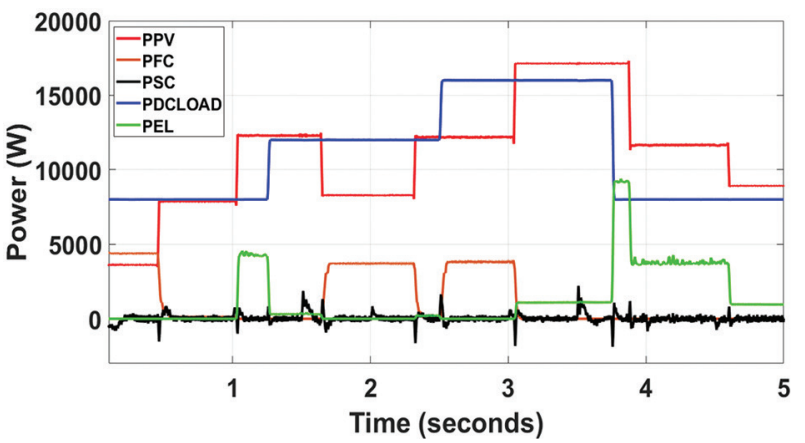

Fig. 8. The power output of PV, FC, EL, SC and DC load
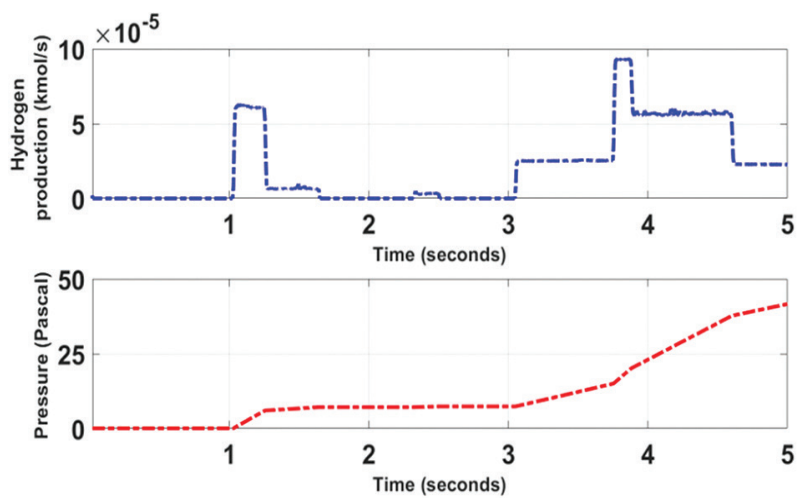

Fig. 9. Hydrogen production and pressure in the tank

In Fig. 10, the variation in AC load, power produced by WECS and the real power balance between MG and the grid are illustrated. The difference in the output power of WECS and the AC load is absorbed/delivered by the utility grid. SC bank provides or absorbs the energy to help the immediate power balance of the AC subgrid by providing and absorbing power from the DC bus as observable in Fig. 10.

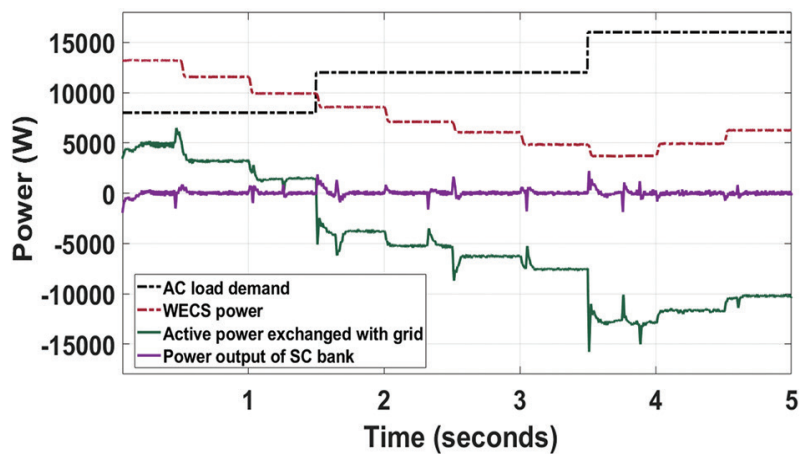

Fig. 10. AC load, power of WECS, power exchanged with grid and SC power

The power shared through the ILC with and without the EL system is shown in Fig. 11. When the EL is absent, the additional produced power in the PV power is transferred to the AC subgrid through ILC. As evident from Fig. 12, the extra power produced by the PV array is sent to the $A C$ subgrid in the absence of the $E L$ system. Thus the amount of power taken from the grid is reduced.

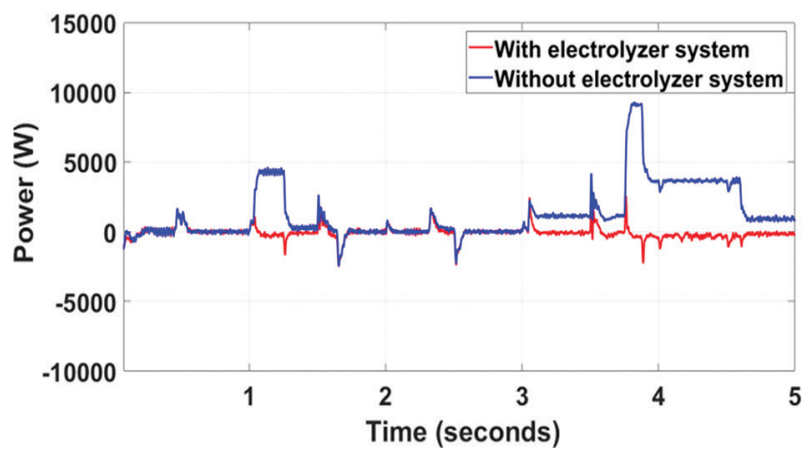

Fig. 11. The power exchanged between $A C$ and DC subgrids 


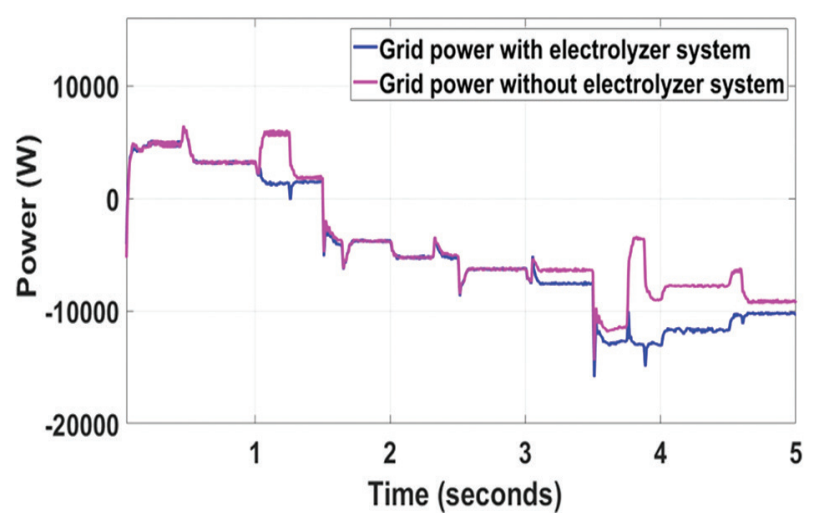

Fig. 12. Grid active power with and without EL system

Reactive power exchange is made zero by keeping $\mathrm{q}$-axis current reference at zero which is presented in Fig. 13.

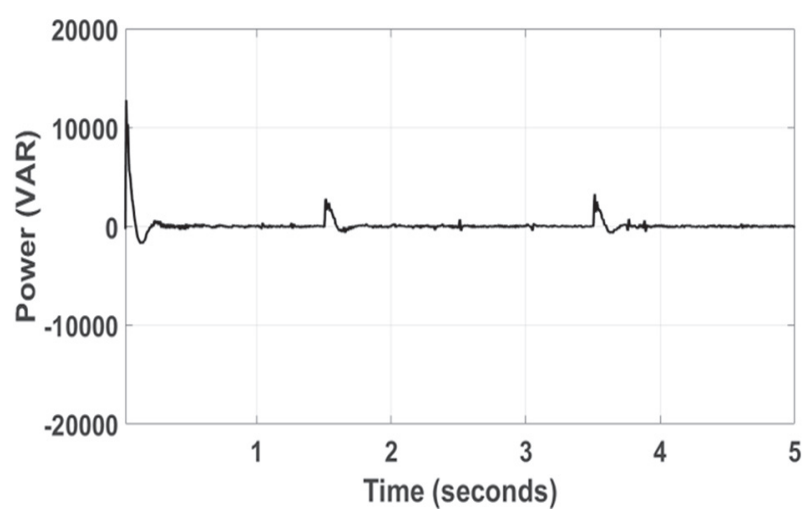

Fig. 13. Reactive power

The $V_{D C}$ is regulated at $800 \mathrm{~V}$ by the $P Q$ controller as shown in Fig. 14. Overshoot is found to be 7.5 percent. It is maintained at the reference value even under fluctuating conditions of source and load.

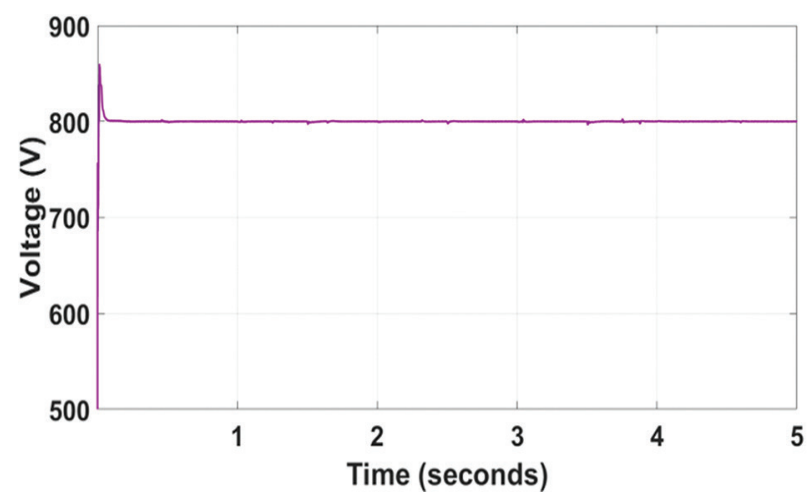

Fig. 14. DC bus voltage

The Bode plots of the filter in the absence and presence of the damping resistor are presented in Fig. 15 and Fig. 16 respectively. It is obvious from the figures that the filter may go unstable without a damping resistor. The filter performs stably with damping as phase margin and gain margin are positive.

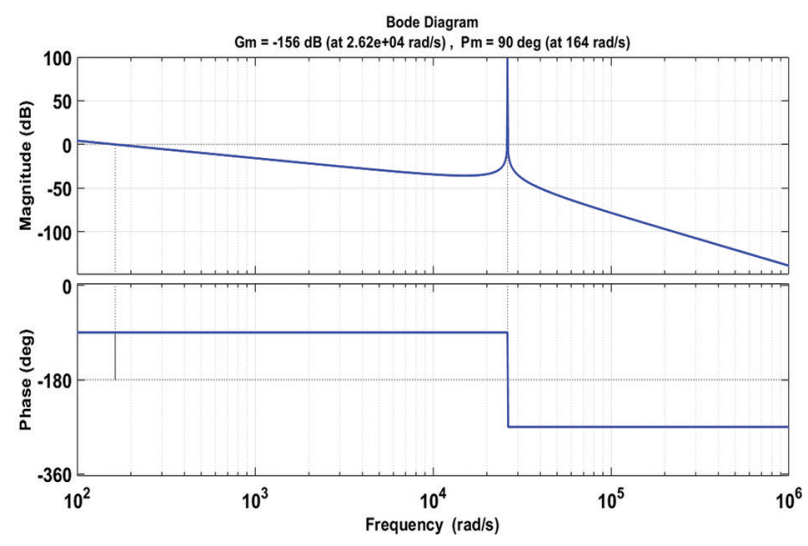

Fig. 15. Bode plot of the filter (in the absence of $R_{d}$ )

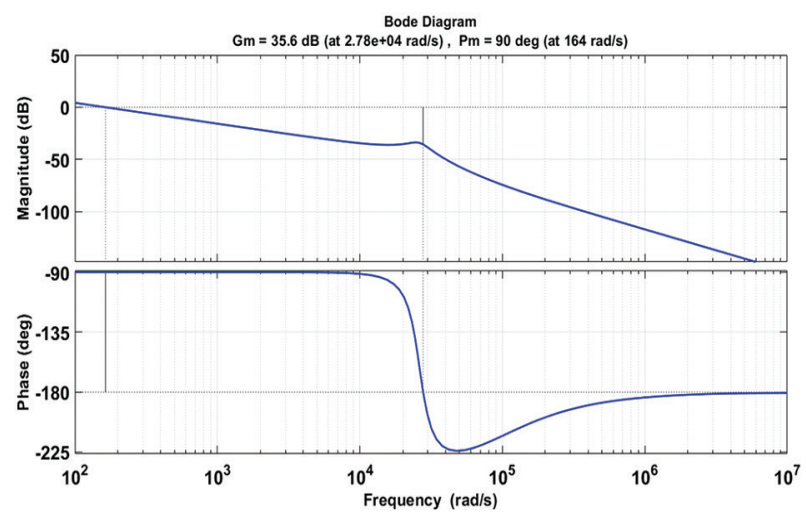

Fig. 16. Bode plot of the filter (in the presence of $R_{d}$ )

Fig. 17 illustrates the harmonic spectrum of the grid current. Total Harmonic Distortion (THD) is lesser than the limit indicated in IEEE standards [32] since an appropriately designed filter is used.

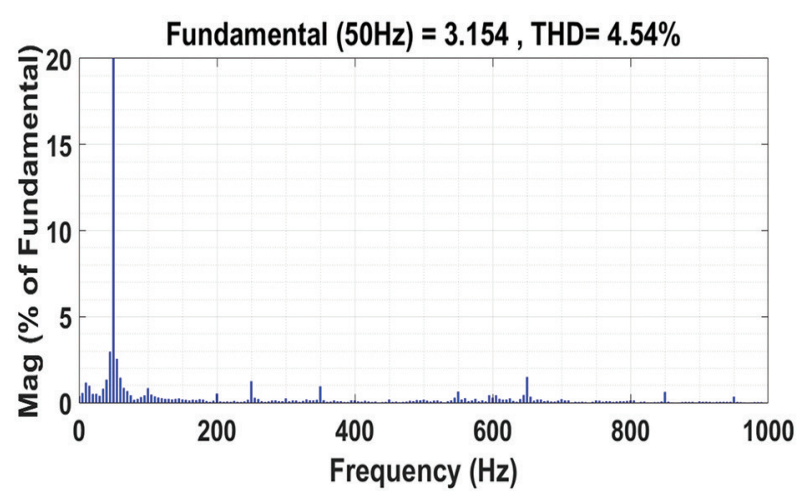

Fig. 17. Harmonic spectrum of grid current

\subsection{BENEFITS OF INCORPORATING SC ON THE HMG}

The HMG can operate even in the absence of SC bank. In Fig. 18 and Fig. 19, the load on the DC bus and power delivered to the load are shown in the absence and presence of the SC bank respectively. Smooth power is supplied to the DC load with very low fluctuations due to dynamic variations in the AC subgrid when the SC system is incorporated into the DC bus as it works quickly to allow immediate power balance. 


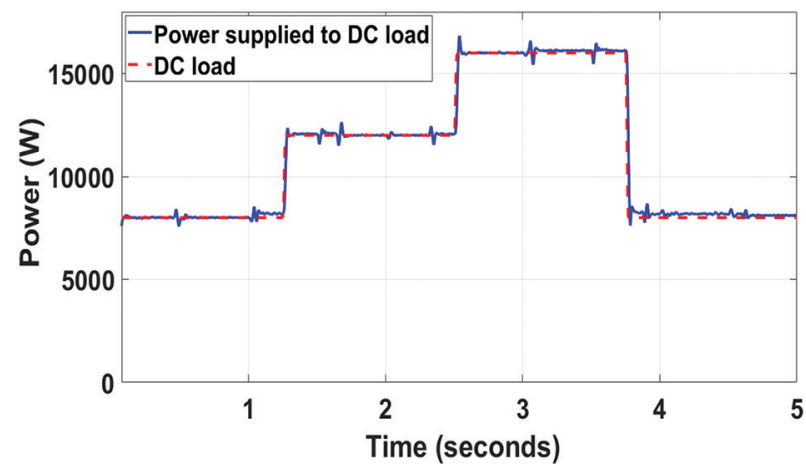

Fig. 18. Power supplied to DC load (in the absence of SC bank)

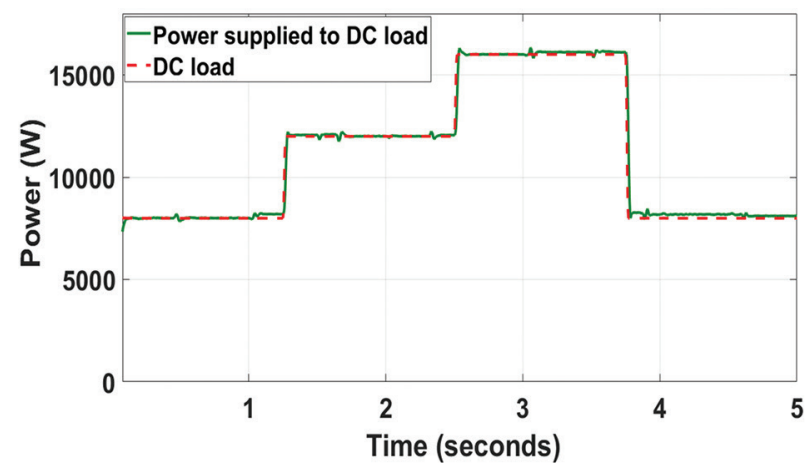

Fig. 19. Power supplied to DC load (in the presence of SC bank)

In Fig. 20, active power exchanged with the grid is shown in the presence and absence of SC bank. It is clear from the picture that the grid experiences fewer transients or stress when SC bank is used in the DC bus.

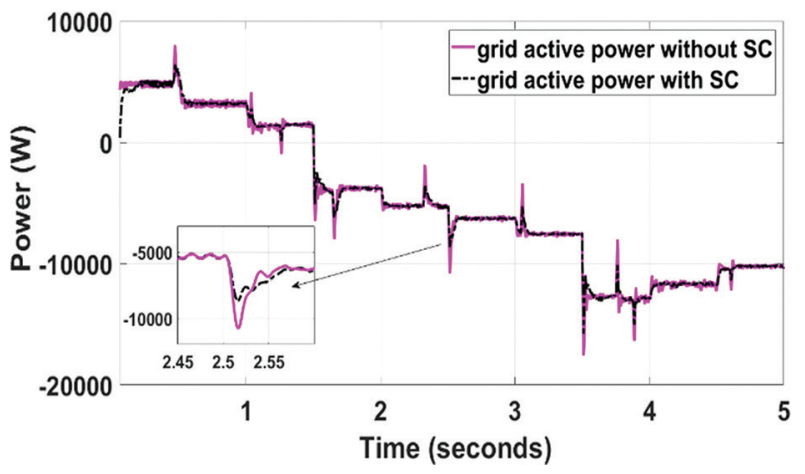

Fig. 20. Active power

(in the presence and absence of SC bank)

Fig. 21 depicts the impact of using the V-I controlled SC bank in the system on the DC bus voltage profile. Fewer fluctuations are observed in the voltage when the SC bank is incorporated. The DC bus voltage variation during the change of load in the presence and absence of SC bank is found to be $3.9 \mathrm{~V}$ and $6.6 \mathrm{~V}$ respectively. Similarly, the maximum transient in the power supplied to the DC load is found to be $830 \mathrm{~W}$ without the incorporation of a controlled SC bank and $340 \mathrm{~W}$ in the presence of the V-I controlled SC bank. Hence it is always preferable to use the SC bank with the control scheme considered in this work in dynamic systems like HMGs involving PV array, WECS and FC characterized by continuously changing load.

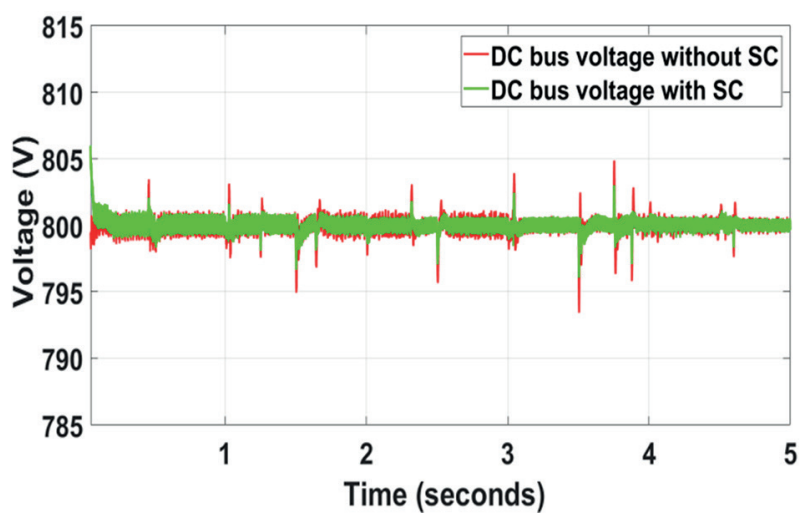

Fig. 21. DC bus voltage with and without SC bank

\section{CONCLUSIONS}

The performance study of a HMG with PV array, WECS and FC under intermittent load demand and power production is detailed in this article. The power-sharing in the HMG is analyzed with and without SC bank. The powerflowamong the $D C$ and $A C$ subgrids in the absence of the EL system is analyzed. By using the properly designed filter, the harmonics in load voltage and grid current are maintained within limits. Coordinated power management in the HMG is accomplished. The major research findings of this work are as follows.

- The SC bank facilitates immediate power balance and reduces the fluctuations in the power supplied to loads in the DC bus which are created by dynamic variations in the $A C$ subgrid.

- By incorporating the SC system on the DC bus, the transient fluctuations in the real power exchanged with the grid are also considerably minimized.

The power smoothing techniques to enhance the performance of the same HMG are under investigation by the authors.

\section{REFERENCES}

[1] M. Uzunoglu, O. C. Onar, M. S. Alam, "Modeling, control and simulation of a PV/FC/UC based hybrid power generation system for stand-alone applications", Renewable energy, Vol. 34, No. 3, 2009, pp. 509-520.

[2] N. S. Jayalakshmi, D. N. Gaonkar, "Operation of grid integrated wind/PV hybrid system with grid perturbations", International Journal of Renewable Energy Research, Vol. 5, No. 4, 2015, pp. 1106-1111. 
[3] M. A. Abdullah, A. H. Yatim, C. W. Tan, R. Saidur, "A review of maximum power point tracking algorithms for wind energy systems", Renewable and Sustainable Energy Reviews, Vol. 16, No. 5, 2012, pp. 3220-3227.

[4] O. C. Onar, M. Uzunoglu, M. S. Alam, "Modeling, control and simulation of an autonomous wind turbine/photovoltaic/fuel cell/ultra-capacitor hybrid power system", Journal of Power Sources, Vol. 185 , No. 2, 2008, pp. 1273-1283.

[5] S. K. Ayyappa, D. N. Gaonkar, "Performance analysis of a variable-speed wind and fuel cell-based hybrid distributed generation system in gridconnected mode of operation", Electric Power Components and Systems, Vol. 44, No. 2, 2016, pp. 142-151.

[6] A. Eid, "Utility integration of PV-wind-fuel cell hybrid distributed generation systems under variable load demands", International Journal of Electrical Power \& Energy Systems, Vol. 62, 2014, pp. 689-699.

[7] W. Bai, M. R. Abedi, K. Y. Lee, “Distributed generation system control strategies with PV and fuel cell in microgrid operation", Control Engineering Practice, Vol. 53, 2016, pp. 184-193.

[8] H. Fathabadi, "Novel standalone hybrid solar/ wind/fuel cell power generation system for remote areas", Solar Energy, Vol. 146, 2017, pp. 3043.

[9] A. F. Bendary, M. M. Ismail, "Battery Charge Management for Hybrid PV/Wind/Fuel Cell with Storage Battery", Energy Procedia, Vol. 162, 2019, pp. 107-116.

[10] X. Liu, P. Wang, P. C. Loh, “A hybrid AC/DC microgrid and its coordination control", IEEE Transactions on Smart Grid, Vol. 2, No. 2, 2011. pp. 278-286.

[11] P. C. Loh, D. Li, Y. K. Chai, F. Blaabjerg "Autonomous operation of hybrid microgrid with $A C$ and $D C$ subgrids", IEEE Transactions on Power Electronics, Vol. 28, No. 5, 2013, pp. 2214-2223.

[12] F. Nejabatkhah, Y. W. Li, "Overview of power management strategies of hybrid AC/DC microgrid", IEEE Transactions on Power Electronics, Vol. 30, No. 12, 2015, pp. 7072-7089.
[13] M. P. Akter, S. Mekhilef, N. M. Tan, H. Akagi, “Model predictive control of bidirectional AC-DC converter for energy storage system", Journal of Electrical Engineering \& Technology, Vol. 10, No. 1, 2015, pp. 165-175.

[14] T. Ma, M. H. Cintuglu, O. A. Mohammed, "Control of a hybrid AC/DC microgrid involving energy storage and pulsed loads", IEEE Transactions on Industry Applications, Vol. 53, No. 1, 2017, pp. 567575.

[15] A. A. Abdelsalam, H. A. Gabbar, A. M. Sharaf, "Performance enhancement of hybrid AC/DC microgrid based D-FACTS", International Journal of Electrical Power \& Energy Systems, Vol. 63, 2014, pp. 382-393.

[16] H. R. Baghaee, M. Mirsalim, G. B. Gharehpetian, H. A. Talebi, "A decentralized power management and sliding mode control strategy for hybrid AC/ DC microgrids including renewable energy resources", IEEE Transactions on Industrial Informatics, 2017. (in Press)

[17] M. Hosseinzadeh F. R. Salmasi, "Robust optimal power management system for a hybrid AC/DC micro-grid", IEEE Transactions on Sustainable Energy, Vol. 6, No. 3, 2015, pp. 675-687.

[18] S. Lim, J. Choi, "LCL filter design for grid connected NPC type three-level inverter", International Journal of Renewable Energy Research, Vol. 5, No. 1, 2015, pp. 45-53.

[19] M. Liserre, F. Blaabjerg, S. Hansen, "Design and control of an LCL-filter-based three-phase active rectifier", IEEE Transactions on Industry Applications, Vol. 41, No. 5, 2005, pp. 1281-1291.

[20] A. Reznik, M. G. Simões, A. Al-Durra, S. M. Muyeen, "LCL filter design and performance analysis for grid-interconnected systems", IEEE Transactions on Industry Applications, Vol. 50, No. 2, 2014, pp. 1225-1232.

[21] S. Mikkili, A. K. Panda, "Real-time implementation of PI and fuzzy logic controllers based shunt active filter control strategies for power quality improvement", International Journal of Electrical Power \& Energy Systems, Vol. 43, No. 1, 2012, pp. 1114-1126. 
[22] P. Bhat Nempu, N. Sabhahit Jayalakshmi, "A new power management strategy for PV-FC-based autonomous DC microgrid", Archives of Electrical Engineering, Vol. 67, No. 4, 2018, pp. 815-828.

[23] T. M. Aljohani, A. F. Ebrahim, O. Mohammed, "Hybrid Microgrid Energy Management and Control Based on Metaheuristic-Driven Vector-Decoupled Algorithm Considering Intermittent Renewable Sources and Electric Vehicles Charging Lot", Energies, Vol. 13, No. 13, 2020, p. 3423.

[24] S. Amirkhan, M. Radmehr, M. Rezanejad, S. Khormali, "A robust control technique for stable operation of a DC/AC hybrid microgrid under parameters and loads variations", International Journal of Electrical Power \& Energy Systems, Vol. 117, 2020, p. 105659.

[25] S. Gangatharan, M. Rengasamy, R. M. Elavarasan, N. Das, E. Hossain, V. M. Sundaram, "A Novel Battery supported Energy Management System for the effective handling of feeble power in Hybrid Microgrid Environment", IEEE Access, Vol. 8, 2020, pp. 217391-217415.

[26] J. Huang, X. Zhang, A. Zhang, P. Wang, “Comprehensive coordinated frequency control of symmetrical CLLC-DC transformer in hybrid AC/DC microgrids", IEEE Transactions on Power Electronics, Vol. 35, No. 10, 2020, pp. 10374-10384.
[27] P. B. Nempu, N. S. Jayalakshmi, “Coordinated Power Management of the Subgrids in a Hybrid ACDC Microgrid with Multiple Renewable Sources", IETE Journal of Research, 2020, pp.1-11.

[28] P. B. Nempu, N. S. Jayalakshmi, K. Shaji, M. Singh, "Fuzzy-PI Controllers for Voltage and Frequency Regulation of a PV-FC Based Autonomous Microgrid", Proceedings of the IEEE International Conference on Distributed Computing, VLSI, Electrical Circuits and Robotics, Manipal, India, 11-12 August 2019, pp. 1-6.

[29] D. W. Hart, "Power electronics", Tata McGraw-Hill Education, 2011.

[30] X. Liu, P. Wang, P. C. Loh, F. Gao, F. H. Choo "Control of hybrid battery/ultra-capacitor energy storage for stand-alone photovoltaic system", Proceedings of the IEEE Energy Conversion Congress and Exposition, Atlanta, GA, USA, 12-16 September 2010, pp. 336-341.

[31] K. Tatjana, "Control of voltage source converters for power system applications", Norwegian University of Science and Technology, Master's thesis, 2011.

[32] ISC Committee, "IEEE standard for interconnecting distributed resources with electric power systems", New York, NY: Institute of Electrical and Electronics Engineers, 2003. 